\title{
THE QUANTITATIVELY MINOR ROLE OF CARBOHYDRATE IN OXIDATIVE METABOLISM BY SKELETAL MUSCLE IN INTACT MAN IN THE BASAL STATE. MEASUREMENTS OF OXYGEN AND GLU- COSE UPTAKE AND CARBON DIOXIDE AND LACTATE PRODUCTION IN THE FOREARM 1, 2
}

\author{
REUBIN ANDRES, ${ }^{3}$ GORDON CADER, AND KENNETH L. ZIERLER
}

\author{
(From the Departments of Environmental Medicine and Medicine, The Johns Hopkins \\ University and Hospital, Baltimore, Md.)
}

(Submitted for publication January 12, 1956; accepted February 29, 1956)

Skeletal muscle accounts for some 40 per cent of body weight. Presumably, by virtue of its bulk as the largest mass of tissue, its metabolism may be a major factor in total body economy and yet surprisingly little is known of the quantitative characteristics of metabolism of skeletal muscle. Studies of excised muscle and its extracts have provided a rich background relating to the metabolic capabilities of muscle. They have shown a great deal about the apparatus with which muscle is equipped to perform its functions in dissimilating metabolites but they fail to reveal the quantitative importance of particular pathways of dissimilation in the total scheme.

Appraisal of metabolism in intact tissues in man has been accomplished by application of the Fick principle in the case of brain (3), heart (4), kidney (5) and liver (6). These studies were antedated by Chauveau (7) who independently formulated the principle credited to Fick and used it to estimate oxygen consumption, carbon dioxide production and glucose uptake by the levator of the upper lip in the intact horse.

In the studies to be reported here this principle has been applied to assess metabolism of muscles of the forearm in intact man. As a prerequisite to observation of metabolism of forearm muscles

1 This work was performed under a contract between the Office of Naval Research, Department of the Navy and The Johns Hopkins University (NR 113-241) and was further supported by grants-in-aid from the National Institutes of Health, Department of Health, Education, and Welfare (H-1327, A-750) and the Muscular Dystrophy Associations of America, Inc.

2 Parts of this study have been presented at the Third Medical Conference of the Muscular Dystrophy Associations of America (1) and at the 74th meeting of the American Physiological Society (2).

3 Public Health Service Research Fellow of the National Heart Institute. under more complicated conditions observations to be reported here were limited to the basal state with the muscle at rest. The main questions to which answers were sought were: 1) What is the oxygen consumption of resting skeletal muscle? and 2) What is the quantitative role of carbohydrate under basal conditions?

\section{METHODS}

Experimental conditions. Fourteen male subjects were studied. Nine were medical students and laboratory colleagues and five were ambulatory convalescent patients. No food was permitted after 6:00 P.M. the previous night. Blood samples were collected between 10:00 A.M. and 1:00 P.M., that is, 16 to 19 hours postprandially. Subjects lay supine in an air-conditioned room maintained at $25^{\circ} \mathrm{C}$. with the arm comfortably supported. The procedure was previously explained to the subjects and there was little overt anxiety. The brachial artery was cannulated with an 18-gauge thin-walled Riley needle so that the tip of the needle lay just proximal to the antecubital crease. Venous blood for measurement of metabolite concentrations was collected through a polyethylene catheter (I. D. $0.86 \mathrm{~mm}$., O. D. $1.27 \mathrm{~mm}$.) passed through a 16-gauge thin-walled needle which had been introduced in a retrograde direction through a large antecubital vein and into one of the deep veins draining the forearm muscles. Another catheter was similarly passed into any superficial forearm vein for the collection of blood used only in validating the blood flow method. Blood flow through wrist and hand was excluded during the experimental periods by a $10-\mathrm{cm}$. wide pressure cuff about the wrist inflated to a pressure at least at $100 \mathrm{~mm}$. $\mathrm{Hg}$ greater than systolic.

Blood flow was measured by the dye-dilution method previously described (8). In brief, a $\mathbf{0 . 2 5}$ per cent aqueous solution of Evans blue dye, T-1824, in 0.9 per cent sodium chloride was introduced continuously at a constant rate into the brachial artery. The dye concentration was measured in two venous blood samples obtained simultaneously. Flow was calculated from the mean dye concentration only if there was good agreement in the two samples (8).

Injection of dye and application of the wrist cuff began five minutes before the first blood collection. Samples of 
arterial and venous blood were usually collected nearly simultaneously, or, at times, two arterial samples bracketed a number of venous samples. In the latter case, arterial concentration at the time of the venous collection was estimated by interpolation. The interval between collection of successive pairs of samples varied from 12 to 60 minutes. On the average, two arterial and three venous samples were collected from each subject.

The blood samples were collected in syringes with dead spaces filled with heparin in isotonic sodium chloride. No metabolic inhibitors were used in the dead space solution. Dead space was measured for each syringe.

The volume of each blood sample was usually $18 \mathrm{ml}$.; in most experiments a total of less than $150 \mathrm{ml}$. of blood was removed. Hematocrit and concentrations of all metabolites and of T-1824 were determined on aliquots of the same sample of blood.

Forearm volume was determined by water displacement of the segment between the proximal margin of the sphygmomanometer cuff at the wrist and the antecubital crease.

Hematocrits were measured in Wintrobe tubes spun at $925 \mathrm{G}$ for one hour and were corrected for 6 per cent trapped plasma.

Chemical methods. Concentrations of $\mathrm{O}_{2}, \mathrm{CO}_{2}$, glucose and lactic acid were measured in whole blood. Immediately after a blood sample was obtained it was mixed in the syringe by swirling with a drop of mercury. Samples for determination of glucose and lactic acid and hematocrit were delivered into chilled test tubes and a measured sample of this blood was hemolyzed by delivery into distilled water. Proteins were precipitated by the Somogyi barium hydroxide-zinc sulfate method (9), the barium hydroxide solution being added immediately after hemolysis. Glucose was determined in the first nine experiments on duplicate samples of the protein-free supernant by Nelson's arsenomolybdate method (10) and in the remainder on triplicate samples by modification of the anthrone methods of Zipf and Waldo (11) and Roe (12). Lactic acid was measured by the method of Barker and Summerson (13). In some the $\mathrm{CuSO}_{4}-\mathrm{Ca}(\mathrm{OH})_{2}$ step was done in duplicate with color development in quadruplicate. In the remainder the entire procedure was carried out in triplicate. Oxygen and carbon dioxide were determined by the Van Slyke-Neill method (14) in triplicate and no values were discarded.

The reproducibility of the chemical methods is given in Table I. In order to simplify the calculations, only a portion of the data was utilized. For each subject, only the first arterial and venous samples were examined, and for both of these, the first two replicates only were considered. From these data the standard deviation (S.D.) of a single determination was calculated as follows: $\sqrt{\frac{\sqrt{2 \mathrm{~d}^{2}}}{2 \mathrm{~N}}}$, where $\mathrm{d}$ is the difference in the estimated concentration in the two replicates of each blood specimen and $\mathrm{N}$ is the number of pairs of replicates used in the calculation. The precision of the methods depends not only upon the reproducibility of replicate determinations, but also upon the number of replicates. Further calculations of precision then are based upon the S.D. derived above and the num- ber of replicates involved in the procedure. Thus: 1) The standard error of the estimate of the mean concentration of a single blood sample, S.E.M., derived from $\mathrm{N}^{\prime}$ replicates is equal to $\frac{\text { S.D. }}{\sqrt{\mathrm{N}^{\prime}}}$. 2) The standard error of the difference in the estimated mean concentrations of two blood samples, that is, of the arterio-venous difference, S.E.M.(A-V), is equal to $\sqrt{2} \times$ S.E.M. 3) The standard error of the mean A-V concentration difference for the entire series of 14 subjects, S.E.M.(mer.), is equal to $\frac{\text { S.E.M.(A-V) }}{\sqrt{N^{\prime \prime}}}$, where $\mathrm{N}^{\prime \prime}$ is the number of pairs of A-V concentration differences for the entire series. The $\mathbf{9 5}$ per cent confidence limits for each of these calculations are approximately equal to the mean \pm twice the appropriate standard error.

It should be pointed out that these estimates of the error of the chemical methods are not to be considered as descriptions of the overall error of the experimental procedure. In the glucose and lactate methods the protein precipitation step was not carried out in replicate and therefore the error of this part of the procedure is not included in the calculations of Table I. Also, the corrections of concentration for the two dilution factors presented in the next section involve error, but these must be quantitatively insignificant. Part of the calculations (Table V) also includes the error of the blood flow method, which may be as large as \pm 20 per cent (8).

The standard errors presented in subsequent tables are calculated from the data presented in those tables and not from the standard errors of the chemical methods of Table I. The variance of the data in Tables III, $\mathrm{V}$ and VII then arises not alone from errors of the chemical methods, but includes all of the errors of the experimental technique as well as the "physiological variations" in individual subjects. Thus a comparison of the standard errors presented in Table III with the S.E.M.(wor.) of Table I, show the former to be larger.

Calculation of the concentration of metabolites in blood or plasma. The measured concentrations were multiplied by two dilution factors:

\section{1) Heparin dilution factor}

$$
=1+\frac{\text { Volume of syringe dead space }}{\text { Volume of collected blood }} \text {. }
$$

For substances whose concentration was measured in plasma rather than in whole blood (Evans blue dye and potassium) the volume of collected plasma was substituted for the volume of collected blood in the equation above. The heparin dilution factor for blood ranged from 1.01 to 1.02 .

\section{2) Dye dilution factor}

$$
=1+\frac{\text { Concentration of dye in injectate }}{\text { Concentration of dye in blood }} \text {. }
$$

This factor corrects for the slight dilution of the inflowing blood by the dye solution. Since the rate of injection in most subjects was only $0.1 \mathrm{ml}$. per min. or about 0.2 per cent of blood flow, this factor amounted to only about 1.002. In the first two subjects however, an injection rate of $1.0 \mathrm{ml}$. per min. was used and here the factor was 
about 1.02. Again, for substances whose concentration was measured in plasma rather than in whole blood the concentration of dye in plasma was substituted for the concentration of dye in blood in the equation. This correction applied only to venous blood, since arterial blood was collected proximal to the site of introduction of the dye solution.

Calculation of the quantity of metabolite used or produced. In the steady state, the rate at which a metabolite is used or produced by a unit mass of tissue is described by

$$
\dot{\mathrm{Q}}=\frac{\mathrm{F}(\mathrm{A}-\mathrm{V})}{\mathrm{M}},
$$

where $\dot{Q}$ is the rate in question, $F$ is blood flow to the tissue of mass $\mathrm{M}, \mathrm{A}$ is the concentration of the metabolite in arterial blood, and $\mathrm{V}$ is its flow-weighted mean concentration in all venous blood draining the tissue.

Depending on the reference desired, two estimates of $\dot{Q}$ are possible. $\quad \dot{Q}_{T}=\frac{F_{T}\left(A-V_{T}\right)}{M_{T}}$ describes the rate of metabolism of all forearm tissues per unit mass of forearm, where the subscript refers to quantities in total forearm. $\dot{Q}_{\mathbf{M}}=\frac{F_{\mathbf{Y}}\left(\mathrm{A}-\mathrm{V}_{\mathbf{M}}\right)}{M_{\mathbf{Y}}}$ describes the rate of metabolism of muscles in the forearm per unit mass of muscle, where the subscript refers to quantities pertinent to muscle. The quantities measured in fact were $F_{T}$, total flow to the forearm; $V_{\mathbf{M}}$, concentration of metabolites in venous blood draining mostly muscle; and $\mathrm{M}_{\mathbf{T}}$, volume or approximate mass of total forearm. Therefore, application of these data directly to the Fick equation leads to an expression which is neither $\dot{\mathbf{Q}}_{\mathrm{T}}$ nor $\dot{\mathbf{Q}}_{\mathbf{M}}$. However, $\dot{\mathbf{Q}}$ has been estimated in this report entirely on the basis of the experimental data. It is likely that this value is too large to represent accurately $\dot{Q}_{\mathrm{T}}$ and too small to represent accurately $\dot{\mathbf{Q}}_{\mathbf{M}}$. Rough estimates of the size of these inaccuracies are possible and a brief resume of reasonable correction factors is considered here.

The forearm may be considered to include bone, muscle, fat and skin. Blood flow through bone has been estimated (15) and for the segment of forearm in the present studies it would be about $0.1 \mathrm{ml}$. per min. and therefore negligible. Skin flow, however, is significant. In Table II are listed various estimates of blood flow through the skin of the forearm. The highest estimate is derived from the data of Cooper, Edholm, and Mottram (20) who measured forearm flow by venous occlusion plethysmography before and after obliteration of skin flow by epinephrine iontophoresis. Their data indicate a relatively linear relation between total forearm flow and flow to muscle over a range of flows. From the regression line of their data it can be calculated that 30 per cent of the total forearm flow in our subjects passed through skin. However, the pertinence of their data to our study is open to question since conditions in the two studies differed in the following respects: (a) The forearm was encased in a water-filled plethysmograph at $34^{\circ}$ in their study and exposed to room air at $25^{\circ}$ in ours. Partition of blood flow between skin and deep tissues might be quite different in the two cases. (b) Intermittent venous occlusion in the plethysmographic method might also affect the partition of blood flow. (c) The plethysmograph encased a forearm volume which was only $420 \mathrm{ml}$, on the average, compared to $1,000 \mathrm{ml}$. in our studies. Inclusion of the upper forearm in the larger volume results in a higher muscle-mass to skin-mass ratio and presumably implies relatively less skin flow. It would appear from examination of all the available data that blood flow to muscle in our studies represented probably 80 to 85 per cent of total forearm flow.

A similarly rough estimate can be made of the mass of muscle perfused. We attempted to measure the volume of intracellular water in the forearm by continuous intraarterial injection of $n$-acetylaminoantipyrine and sucrose (see [8] for theory) but the results were erratic and useless for this purpose. The only available means of estimating forearm muscle mass lies in data from dissected forearms. Abramson and Ferris (22) found that forearm muscles occupied 58.6 per cent of forearm volume, on the average, and Cooper, Edholm, and Mottram (20) found 63.6 per cent, on the average, in five forearms. The standard deviation of the latter series, calculated from their data, is 6.5 so that one might expect occasional subjects to have values as low as $\mathbf{5 0}$ or as high as $\mathbf{7 5}$ per cent muscle mass in total forearm.

When estimates of flow through muscle and of muscle mass are combined, the expression for rate of metabolism per unit mass of muscle is

$$
\dot{Q}_{\mathbf{M}}=\frac{a}{b} \frac{F_{T}\left(A-V_{M}\right)}{M_{T}},
$$

where $a$ is the fraction of total flow which perfuses muscle and $b$ is the fraction of total forearm which is muscle mass. If representative values of $\mathbf{0 . 8 2}$ and $\mathbf{0 . 6}$ are used for $a$ and b, respectively, the values reported here for $\dot{Q}$ are to be multiplied by 1.37 to convert them to units of metabolic activity per minute per $100 \mathrm{~g}$. muscle, but the factor might be as low as 1.0 or as high as $\mathbf{1 . 7}$.

It is even more difficult to arrive at a reasonable estimate

TABLE I

Estimate of precision of chemical methods *

\begin{tabular}{lccccc}
\hline \hline Method & S.D. & $\begin{array}{c}\text { Number of } \\
\text { replicates }\end{array}$ & S.E.M. & S.E.M.(A-v) & S.E.M.(ox.) \\
\hline Glucose-Nelson & 0.125 & 2 & 0.088 & 0.125 & 0.020 \\
Glucose-Anthrone & 0.079 & 3 & 0.046 & 0.065 & 0.027 \\
Lactate & 0.034 & 3 & 0.019 & 0.027 & 0.005 \\
Oxygen & 0.152 & 3 & 0.088 & 0.124 & 0.023 \\
Carbon dioxide & 0.229 & 3 & 0.132 & 0.187 & 0.035
\end{tabular}

* Values are expressed as mM per 1 . See text for method of calculation and explanation of symbols. 
TABLE II

Estimates of blood flow through skin of forearm

\begin{tabular}{|c|c|c|c|c|}
\hline Reference & $\begin{array}{l}\text { Blood flow } \\
m l . / m i n . / c m .2\end{array}$ & $\begin{array}{l}\text { \% of Fore- } \\
\text { arm blood } \\
\text { flow }\end{array}$ & $\begin{array}{c}\text { Room } \\
\text { temperature } \\
\boldsymbol{c}_{C} \text {. }\end{array}$ & Method \\
\hline $\begin{array}{l}(16) \\
(17)\end{array}$ & $\begin{array}{l}0.015 \\
0.009 \\
0.005\end{array}$ & $\begin{array}{r}22 \\
14 \\
8\end{array}$ & $\begin{array}{l}25 \\
25 \\
25\end{array}$ & \multirow{2}{*}{$\begin{array}{l}\text { Calorimetry } \\
\text { Helium uptake } \\
\text { Rectal and skin temperature } \\
\text { and } \mathrm{O}_{2} \text { uptake } \\
\text { Photoelectric plethysmograph }\end{array}$} \\
\hline & $\begin{array}{l}0.021 \\
0.010\end{array}$ & $15^{*}$ & $\begin{array}{c}30-34 \\
25 \dagger\end{array}$ & \\
\hline (20) & 0.022 & 30 & 24 & $\begin{array}{l}\text { Water filled venous occlusion } \\
\text { plethysmograph with epi- } \\
\text { nephrine iontophoresis }\end{array}$ \\
\hline
\end{tabular}

* The authors in a more recent paper (21) indicate that the factor previously used by them to convert "filter units" to flow was too high, so that the value of 15 per cent is probably somewhat high.

+ Conversion to $25^{\circ}$ made on basis of evidence $(16,17)$ that skin flow at $25^{\circ}$ is one-third the skin flow at $35^{\circ}$.

of corrections which might yield approximate values for $\grave{Q}_{\text {T. }}$ The A-V oxygen difference for skin has been reported to be about half that for muscle (20). If one is willing to make the broad assumption that $A-V$ differences for other metabolites are reduced similarly, then assuming 18 per cent of total forearm flow perfuses skin and 82 per cent perfuses muscle, appropriate substitution of these values yields

$$
Q_{T}=\frac{0.9 F_{T}\left(A-V_{\mathbf{L}}\right)}{M_{T}} .
$$

Thus, it is likely that the experimental values for $\dot{Q}$ more nearly represent metabolic activity of the forearm than of its muscle. However, comparison of $\dot{Q}$ for one metabolite with $\dot{Q}$ for a second metabolite may be expected to reflect adequately their relative values in muscle metabolism since the factors $F$ and $M$ cancel out of any ratio of $\dot{Q}$ 's. It is this advantage which made it desirable to sample specifically from venous blood draining muscle.

\section{RESULTS AND DISCUSSION}

\section{$A-V$ differences}

Concentrations of $\mathrm{O}_{2}, \mathrm{CO}_{2}$, glucose and lactate in arterial blood and the $\mathrm{A}-\mathrm{V}$ concentration differences of these substances determined in each subject are listed in Table III.

With respect to concentration of the several substances measured in arterial blood it may be stated that $\mathrm{O}_{2}$ concentrations were appropriate to the measured hematocrits in each case. The range of total $\mathrm{CO}_{2}$ content was normal for whole blood (23). Glucose concentrations, in more familiar units, were between 82 and $95 \mathrm{mg}$. per $100 \mathrm{ml}$. The arterial lactate concentration can be compared

TABLE III

Arterial concentrations and $A-V$ differences in forearm blood *

\begin{tabular}{|c|c|c|c|c|c|c|c|c|}
\hline \multirow{2}{*}{$\begin{array}{l}\text { Subject } \\
\text { No. }\end{array}$} & \multicolumn{2}{|c|}{$\mathrm{O}_{2}$} & \multicolumn{2}{|c|}{$\mathrm{CO}_{2}$} & \multicolumn{2}{|c|}{ Glucose } & \multicolumn{2}{|c|}{ Lactate } \\
\hline & $\mathbf{A}$ & A-V & $\mathbf{A}$ & V-A & $\mathbf{A}$ & A-V & $\mathbf{A}$ & V-A \\
\hline $\begin{array}{c}1 \\
2 \\
3 \\
4 \\
5 \\
6 \\
7 \\
8 \\
9 \\
10 \\
11 \\
12 \\
13 \\
14 \\
\text { Mean } \\
\pm \text { SEM }\end{array}$ & $\begin{array}{r}9.01 \\
8.35 \\
8.20 \\
8.62 \\
7.38 \\
8.70 \\
7.56 \\
9.44 \\
8.86 \\
7.10 \\
7.01 \\
8.54 \\
9.75 \\
9.55 \\
8.43 \\
\\
(18.9)\end{array}$ & $\begin{array}{l}2.38 \\
1.53 \\
2.06 \\
4.75 \\
2.54 \\
5.05 \\
4.25 \\
3.00 \\
1.86 \\
5.15 \\
3.73 \\
3.69 \\
2.41 \\
2.95 \\
3.24 \\
0.323 \\
(7.3)\end{array}$ & $\begin{array}{l}21.6 \\
23.3 \\
20.1 \\
22.3 \\
21.2 \\
23.0 \\
21.0 \\
22.4 \\
22.3 \\
24.7 \\
22.5 \\
20.3 \\
22.1 \\
21.4 \\
22.0 \\
\\
(48.9)\end{array}$ & $\begin{array}{l}1.85 \\
1.39 \\
2.10 \\
3.18 \\
2.04 \\
3.24 \\
3.22 \\
1.95 \\
1.44 \\
3.78 \\
2.75 \\
3.20 \\
2.21 \\
2.60 \\
2.50 \\
0.200 \\
(5.6)\end{array}$ & $\begin{array}{l}4.75 \\
5.12 \\
4.83 \\
4.92 \\
4.54 \\
4.95 \\
5.18 \\
4.88 \\
4.99 \\
4.76 \\
4.73 \\
4.70 \\
4.82 \\
5.29 \\
4.89 \\
\\
(88)\end{array}$ & $\begin{array}{r}0.25 \\
0.15 \\
-0.01 \\
0.13 \\
0.05 \\
0.23 \\
-0.06 \\
0.25 \\
0.04 \\
0.15 \\
0.09 \\
-0.04 \\
-0.04 \\
0.10 \\
0.09 \\
0.029 \\
(1.7)\end{array}$ & $\begin{array}{l}0.70 \\
0.60 \\
0.98 \\
0.70 \\
0.69 \\
0.57 \\
0.63 \\
0.45 \\
0.54 \\
1.19 \\
0.37 \\
0.49 \\
0.56 \\
0.88 \\
0.67 \\
(6.0)\end{array}$ & $\begin{array}{l}0.05 \\
0.13 \\
0.02 \\
0.25 \\
0.16 \\
0.00 \\
0.19 \\
0.13 \\
0.06 \\
0.05 \\
0.07 \\
0.14 \\
0.27 \\
0.06 \\
0.11 \\
0.022 \\
(1.0)\end{array}$ \\
\hline
\end{tabular}

* All values expressed as $\mathrm{mM}$ per 1 . All values have been calculated to one decimal place beyond those listed in he table for use in subsequently derived data. Data in parentheses are mean values re-expressed as $\mathrm{ml}$. per $100 \mathrm{ml}$. for the gases and as $\mathrm{mg}$. per $100 \mathrm{ml}$. for the carbohydrates. 
only to a few studies employing the more specific method available in recent years. The mean value, $0.67 \mathrm{mM}$ per 1 . or $6 \mathrm{mg}$. per $100 \mathrm{ml}$., is the same as that obtained by Mitchell and Cournand (24) on three subjects but is lower than the mean of 9.1 obtained on 22 subjects by Ungar, Gilbert, Siegel, Blain, and Bing (25) and much lower than the mean of $19 \mathrm{mg}$. per $100 \mathrm{ml}$. found in fingertip capillary blood by Hummel (26). While capillary blood may be a useful substitute for arterial blood in certain circumstances it is inappropriate in the case of lactate determinations. Skin shows active anaerobic glycolysis (27) and lactate on skin surface is an important contaminant in the analysis of lactate (13).

Since the validity of the Fick principle depends upon the existence of a steady-state, it is important to determine whether or not the concentration of metabolites in arterial blood was reasonably constant during these experiments. Changes in arterial concentrations are presented in Table IV. There was no consistent upward or downward trend in arterial concentration of any of the metabolites and indeed in all cases the arterial concentrations were quite constant. This constancy supports the impression that there was little disturbing anxiety over the procedure among the subjects.

$\mathrm{O}_{2} \mathrm{~A}-\mathrm{V}$ difference. The mean difference, 3.2 $\mathrm{mM}$ per 1 . or $7.3 \mathrm{ml}$. per $100 \mathrm{ml}$, represents extraction of some 40 per cent of the oxygen delivered to the muscles of the forearm.

Of historical interest in this connection is the report by Christison in 1831 (28) in which the peripheral $\mathrm{A}-\mathrm{V} \mathrm{O} \mathrm{O}_{2}$ difference was estimated at $12 \mathrm{ml}$. per $100 \mathrm{ml}$. by measuring the additional quantity of $\mathrm{O}_{2}$ which venous blood could accu-

TABLE IV

Constancy of arterial concentration *

\begin{tabular}{|c|c|c|}
\hline & $\begin{array}{l}\text { Absolute change } \\
\mu M / m l . b l o o d / m i x .\end{array}$ & $\begin{array}{c}\text { Relative change } \\
\% / \text { min. }\end{array}$ \\
\hline $\begin{array}{l}\mathrm{O}_{2} \\
\mathrm{CO}_{2} \\
\text { Glucose } \\
\text { Lactate }\end{array}$ & $\begin{array}{c}-0.007 \pm 0.004 \\
-0.009 \pm 0.006 \\
-0.001 \pm 0.002 \\
0 \quad \pm 0.001\end{array}$ & $\begin{array}{c}-0.08 \pm 0.05 \\
-0.04 \pm 0.03 \\
-0.02 \pm 0.04 \\
0 \pm 0.15\end{array}$ \\
\hline
\end{tabular}

* Absolute change refers to change in concentration in subsequent samples compared to the concentration in the preceding sample drawn from each subject and expressed per minute time interval between sampling. Relative change refers to absolute change as per cent of mean arterial concentration. mulate. Christison anticipated Chauveau and Fick by noting that the venous blood from subjects in whom peripheral blood flow was obviously increased accepted less additional oxygen than normal.

The mean $\mathrm{A}-\mathrm{V} \mathrm{O}_{2}$ difference in the present study of $7.3 \mathrm{ml}$. per $100 \mathrm{ml}$. is somewhat higher than the 4.6 to $5.5 \mathrm{ml}$. per $100 \mathrm{ml}$. value obtained in most previous reports (29-31); collection of blood from a deep vein and exclusion of blood flow from the hand, both of which increased the A-V difference by minimizing contamination of venous blood by blood from skin with its higher $\mathrm{O}_{2}$ content, probably account for this difference. Mottram (32), however, aware of the need for these precautions, obtained a mean value of $\mathbf{8 . 5}$ $\mathrm{ml}$. per $100 \mathrm{ml}$. Blood flow was somewhat less in his subjects and arterial $\mathrm{O}_{2}$ content was estimated by assuming 95 per cent arterial saturation and measuring the $\mathrm{O}_{2}$ capacity of venous blood. A mean value of about $5.3 \mathrm{ml}$. per $100 \mathrm{ml}$. has been found in blood obtained from femoral artery and vein $(31,33,34)$.

$\mathrm{CO}_{2} \mathrm{~A}-\mathrm{V}$ difference. This has rarely been estimated. Harrop in 1919 (30) and Peters, Barr, and Rule in 1921 (35) reported mean differences of -5.0 and $-6.8 \mathrm{ml}$. per $100 \mathrm{ml}$, respectively, which are comparable to the mean value of -5.6 $\mathrm{ml}$. per $100 \mathrm{ml}$. in the present study.

Glucose A-V difference. Data on glucose A-V differences are abundant. An extensive series was gathered by Somogyi in 1948 (36) and a mean difference between finger capillary blood and antecubital venous blood of $5 \mathrm{mg}$. per 100 ml. was obtained. Bell in 1952 (34) found a mean difference of $2.2 \mathrm{mg}$. per $100 \mathrm{ml}$. between femoral arterial and venous blood. The mean in the present series, $0.093 \mathrm{mM}$ per 1 . or $1.7 \mathrm{mg}$. per $100 \mathrm{ml}$., and the range agree closely with Bell's data. The several negative A-V differences obtained by Bell and by us are small. Although they are probably within experimental error, the possibility remains that they are real.

Lactate $A-V$ differences. In all subjects venous lactate concentration was always higher than arterial; that is, forearm muscles at rest produced lactate continuously even in the presence of active oxygen consumption.

The presence of lactic acid at all times in circulating blood has been attributed to its formation 
by "a few special tissues, such as red blood cells, the intestinal mucous membrane, and the retina, etc." (37). In the light of the present data resting skeletal muscle must now be considered as a major source of lactate in blood in the basal state. The accepted concept that lactate formation in muscle is a sign of anoxia must also be modified. There was, in fact, no correlation between lactate and $\mathrm{O}_{2} \mathrm{~A}-\mathrm{V}$ differences in the present study.

\section{Rates of uptake or production}

Values for forearm blood flow, rates of uptake of $\mathrm{O}_{2}$ and of glucose and rates of production of $\mathrm{CO}_{2}$ and of lactate $\left(\dot{Q}_{\mathrm{O}_{2}}, \dot{Q}_{\mathrm{G}}, \dot{Q}_{\mathrm{CO}_{2}}\right.$ and $\dot{Q}_{\mathrm{I}}$, respectively), expressed as the mean for eight of the subjects, appear in Table V. In accordance with criteria previously established (8) blood flow was not calculated in six subjects: in four, only one vein was catheterized; in two, dye concentrations in blood from the two veins differed by more than 20 per cent.

Blood flow. The range of blood flows in these subjects was similar to normal values established previously by the indicator-dilution method (8). Blood flow was quite constant during the experimental period and there was no trend toward increasing or decreasing flow. The mean change in blood flow in all subjects was $-0.035 \mathrm{ml}$. per min. per $100 \mathrm{ml}$. forearm \pm 0.028 (S.E.M.), or a rate of change of about -1 per cent per min. \pm 0.8 .

$\mathrm{O}_{2}$ uptake. The only previous studies in which blood flow and peripheral A-V differences have been measured simultaneously in man are two which were concerned only with $\mathrm{O}_{2}$ uptake. Holling (38) found a mean $\dot{Q}_{O_{2}}$ of $0.12 \mathrm{ml}$. per min. per $100 \mathrm{ml}$. forearm tissue and Mottram (32) found a mean $\dot{Q}_{\mathrm{O}_{2}}$ of $0.24 \mathrm{ml}$. per min. per $100 \mathrm{ml}$. forearm muscle. When the latter data are recalculated, using the means of the total forearm blood flow and $\mathrm{A}-\mathrm{V} \mathrm{O}_{2}$ difference, one obtains a value of $0.27 \mathrm{ml}$. per min. per $100 \mathrm{ml}$. forearm. This is remarkably similar to the value reported here, $11.7 \mathrm{mM}$ or $0.26 \mathrm{ml}$. per min. per $100 \mathrm{ml}$. forearm.

It has been suggested earlier (see Methods) that the values given here for $\dot{Q}$ may be too small by a factor of about one-third to represent metabolic activity in muscle proper. If the value
TABLE V

Uptake of $\mathrm{O}_{2}$ and glucose and production of $\mathrm{CO}_{2}$ and lactate by forearm *

\begin{tabular}{cccccc}
\hline $\begin{array}{c}\text { Subject } \\
\text { No. }\end{array}$ & $\begin{array}{c}\text { Blood } \\
\text { flow }\end{array}$ & \multicolumn{1}{c}{$\mathrm{O}_{2}$} & $\mathrm{CO}_{2}$ & Glucose & Lactate \\
\hline 1 & 4.3 & 10.7 & 8.5 & 1.09 & 0.20 \\
4 & 3.2 & 15.0 & 10.0 & 0.42 & 0.78 \\
6 & 2.6 & 13.3 & 8.6 & 0.62 & 0.02 \\
8 & 1.9 & 6.4 & 4.1 & 0.44 & 0.26 \\
9 & 5.0 & 9.8 & 7.6 & 0.18 & 0.29 \\
10 & 3.5 & 18.2 & 13.4 & 0.53 & 0.18 \\
12 & 4.8 & 11.9 & 10.3 & -0.11 & 0.68 \\
13 & 3.4 & 8.2 & 7.5 & -0.15 & 0.92 \\
Mean & 3.6 & 11.7 & 8.7 & 0.38 & 0.42 \\
ISEM & & 1.34 & 0.94 & 0.143 & 0.116 \\
& & $(0.262)$ & $(0.194)$ & $(0.068)$ & $(0.037)$
\end{tabular}

* Subject No. same as in Table III. Blood flow expressed as ml. whole blood per min. per $100 \mathrm{ml}$. forearm. Uptake and production data expressed as $\mu \mathrm{M}$ per min. per $100 \mathrm{ml}$. forearm. Data in parentheses are mean values reexpressed as $\mathrm{ml}$. per min. per $100 \mathrm{ml}$. forearm for the gases and as $\mathrm{mg}$. per min. per $100 \mathrm{ml}$. forearm for the carbohydrates.

given for $\dot{Q}_{O_{2}}$ is increased by one-third, the estimate of $\dot{Q}_{O_{2}}$ for skeletal muscle becomes $15.5 \mu \mathrm{M}$ or $0.35 \mathrm{ml}$. per min. per $100 \mathrm{~g}$. forearm muscle. If it is assumed that an ideal man of $1.73 \mathrm{M}^{2}$ body surface weighs $63 \mathrm{Kg}$. and that he is 40 per cent skeletal muscle, and if metabolism in forearm muscles is fairly representative of the $25 \mathrm{Kg}$. of body muscle, then the total $\mathrm{O}_{2}$ consumption by skeletal muscle in ideal man is 3.9 $\mathrm{mM}$ or $88 \mathrm{ml}$. per min. This rate of $\mathrm{O}_{2}$ consumption by skeletal muscle is 35 to 40 per cent of standard basal total body $\mathrm{O}_{2}$ consumption. In Table VI this datum is added to those reported for other organs and it will be noted that the sum of the parts compares well with the whole.

Glucose uptake. Similar calculations may be made for glucose uptake by muscle proper.

TABLE VI

Summary of the metabolism of oxygen and glucose in intact organs of man in the basal state

\begin{tabular}{|c|c|c|}
\hline & $\underset{m l . / \min . / 1.73 \mathrm{ML}^{2}}{\dot{\phi}_{2}}$ & $\underset{m g . / m i n . / 1.73 M^{2}}{\dot{Q}_{a}}$ \\
\hline Total body & $234(0)$ & $112 *(10)$ \\
\hline $\begin{array}{l}\text { Splanchnic bed } \\
\text { Brain } \\
\text { Kidney } \\
\text { Heart } \\
\text { Muscle }\end{array}$ & $\begin{array}{l}59(10) \\
48(41) \\
13(18) \\
31^{(25)} \\
88\end{array}$ & $\begin{array}{c}78(41) \\
\text { "negligible" (4s) } \\
14(25) \\
22\end{array}$ \\
\hline tissues & 239 & 114 \\
\hline
\end{tabular}

* Glucose output by splanchnic bed.

Figures in parentheses are reference numbers. 
These lead to estimates of $0.5 \mu \mathrm{M}$ or $0.09 \mathrm{mg}$. of glucose taken up per minute per $100 \mathrm{~g}$. forearm muscle, and of $22 \mathrm{mg}$. per min. for glucose uptake by total muscle in ideal man. In Table VI this value for glucose uptake by muscle is added to those available for brain and heart. Their sum agrees well with the estimated rate of release of glucose by liver.

The fraction of $\mathrm{O}_{2}$ consumption accounted for by oxidation of glucose and the fraction of glucose uptake accounted for by lactate production

The uptake of glucose and of oxygen may be directly compared from data in Table III. If all glucose taken up were completely oxidized, then it would account for only 19 per cent of the oxygen consumption, on the average. It has, however, been shown that lactate is continuously produced by forearm tissues, and it is therefore reasonable to assume that even 19 per cent is an overestimate, since apparently not all the glucose undergoes oxidation.

A more precise appraisal may be derived using the following assumptions: (a) muscle glycogen is constant during these observations, (b) lactate arises exclusively from dissimilation of glucose, and (c) diffusible intermediates other than lactate are negligible.

The essence of the calculation about to be made is that one first determines the fraction of glucose uptake which can be accounted for by lactate production. The remainder of the glucose uptake is then assumed to be oxidized completely. If assumption (b) is sufficiently in error anaerobic dissimilation of glucose will be overestimated, but this appears to be a quite reasonable assumption. Assumption (c) is probably overdrawn in that pyruvate for example is known to be diffusible and might account for an additional moiety of glucose. It is probable that this is small. The error leads to a slight overestimate of the fraction of glucose which is oxidized.

Since production of 2 moles of lactate implies dissimilation of 1 mole of glucose, lactate molar $\mathrm{A}-\mathrm{V}$ differences are divided by two to determine the size of the glucose $A-V$ difference which is exactly matched by lactate production. The following equations apply:
$\frac{(\mathrm{V}-\mathrm{A})_{\mathrm{L}}}{2(\mathrm{~A}-\mathrm{V})_{\mathrm{G}}} 100$, the per cent of glucose uptake accounted for by anaerobic metabolism or by lactate production, and

$\frac{6\left[(\mathrm{~A}-\mathrm{V})_{\mathrm{G}}-\frac{1}{2}(\mathrm{~V}-\mathrm{A})_{\mathrm{L}}\right]}{(\mathrm{A}-\mathrm{V})_{\mathrm{O}_{2}}} 100$, the per cent of $\mathrm{O}_{2}$ consumption accounted for by oxidation of glucose abstracted from blood.

These estimates are presented in Figure 1 and in Table VII.

It will be seen that about 60 per cent of glucose uptake is accounted for by lactate production.

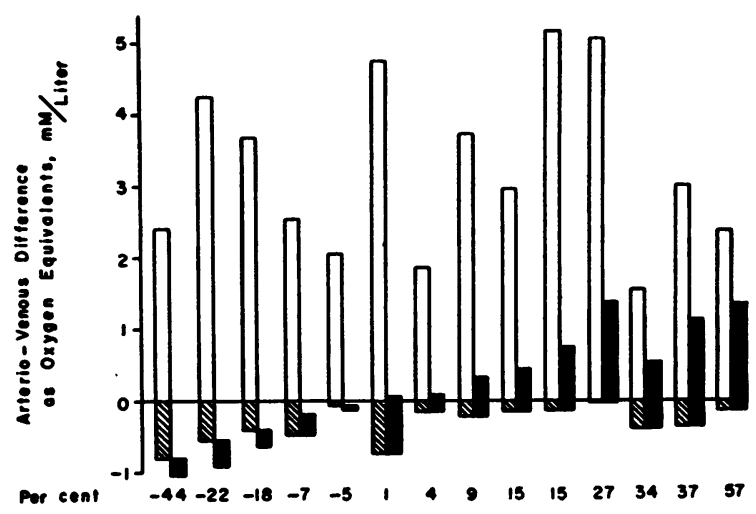

Fig. 1. The Fraction of Oxygen Consumption Accounted for by Oxidation of Glucose in the RestING FOREARM

Each pair of columns represents data from a single subject. Each left-hand column of the pair contains two components: the arteriovenous difference in oxygen concentration, $\mathrm{mM}$ per 1 ., is represented by the column above the zero line, and the oxygen equivalents of the arteriovenous difference in lactate concentration (the measured arteriovenous difference in lactate multiplied by 3) is represented by the column below the zero line. Each right-hand column of the pair represents the oxygen equivalents of the arteriovenous difference in glucose concentration (the measured arteriovenous difference in glucose multiplied by 6 ). The base of each right-hand column is aligned so that all the glucose uptake accounted for by lactate production appears below the zero line; the remaining glucose uptake, available for oxidation, appears above the zero line. In four subjects the venous glucose concentration exceeded the arterial and in these the glucose bar is plotted down from the base of the lactate bar. The numbers below the pairs of columns indicate the per cent of oxygen consumption accounted for by oxidation of glucose.

Data on nine subjects in this figure have appeared previously in Figure 1, reference (1). In some of these, recalculation of the data has led to slight revision. Data on a tenth subject previously reported (1) have been deleted owing to the fact that he had not fasted 16 hours. 
TABLE VII

The fraction of glucose uptake accounted for by lactate production, the fraction of oxygen uptake accounted for by glucose oxidation, and the respiratory quotient of forearm *

\begin{tabular}{rrrl}
\hline \hline $\begin{array}{c}\text { Subject } \\
\text { No. }\end{array}$ & L/G & (G-L)/Oz & R.Q. \\
\hline 1 & 9 & 57 & 0.79 \\
2 & 44 & 34 & 0.91 \\
3 & All & -5 & 1.02 \\
4 & 94 & 1 & 0.67 \\
5 & 163 & -7 & 0.80 \\
6 & 1 & 27 & 0.64 \\
7 & All & -22 & 0.76 \\
8 & 26 & 37 & 0.65 \\
9 & 72 & 4 & 0.77 \\
10 & 17 & 15 & 0.73 \\
11 & 41 & 9 & 0.74 \\
12 & All & -18 & 0.87 \\
13 & All & -44 & 0.92 \\
14 & 28 & 15 & 0.88 \\
& & & \\
Mean & 61 & 7.4 & 0.797 \\
土SEM & 13 & 7.07 & 0.0297 \\
\hline
\end{tabular}

* $\mathrm{L} / \mathrm{G}=100$ (1/2 lactate $\mathrm{V}-\mathrm{A}$ difference)/(Glucose $\mathrm{A}-\mathrm{V}$ difference). In subjects $3,7,12$, and 13 the $A-V$ glucose differences were negative. Mean value for $L / G$ is calculated from the mean lactate $\mathrm{V}$-A difference and the mean glucose A-V difference, and its SEM calculated from variance of $A-V$ lactate and of $A-V$ glucose differences. $(\mathrm{G}-\mathrm{L}) / \mathrm{O}_{2}=$ fraction of oxygen uptake accounted for by glucose oxidation, calculated as explained in the text.

This is a surprisingly high value. The classical view is that "lactate formation in tissues is a sign of anoxia, for in the presence of oxygen pyruvate proceeds through the oxidative pathway" (44). The lactate formation in working muscles, for example, is attributed to the inability of the blood supply to meet the increased oxygen requirements. Yet, the forearm muscles were at rest, blood flow was normal, and oxygen consumption was brisk, although the technique used cannot rule out the possibility that lactate is formed during periods of ischemia, perhaps as blood flow shifts from one area of muscle to another.

It may be suspected that the high concentrations of lactate in venous blood resulted possibly from escape of small amounts of blood from the ischemic hand or from a relatively ischemic wedge of tissue beneath the proximal edge of the sphygmomanometer cuff at the wrist. The former possibility seems unlikely in the light of the following observation. A small amount of an aqueous solution of $\mathrm{Na}_{2} \mathrm{~S}^{35} \mathrm{O}_{4}$ was injected intramuscularly into the thenar eminence of a subject in whom hand circulation was occluded by a pressure cuff at the wrist. No radioactivity was detected in ante- cubital venous blood during the usual period of occlusion, but on release of the cuff there was the anticipated rush of radioactivity into antecubital venous blood. The possibility that high venous lactate concentration represented lactate contributed from an ischemic wedge of tissue beneath the cuff was made unlikely by an experiment in which the cuff was not applied. The concentration of lactate in the deep venous blood again exceeded the concentration in arterial blood. And finally, it will be recalled from Table IV that blood lactate concentrations were quite constant and from Table III that the concentrations reported here are at least as low, if not lower, than those reported by others for subjects at rest in the fasting state.

Equally surprising is the fact that only about 7 per cent of the oxygen consumption of the forearm muscles is spent in oxidation of glucose. The range of results, +57 to -44 per cent is attributable in part to cumulative experimental errors of determinations of glucose, lactate and $\mathrm{O}_{2}$ in arterial and venous blood. These errors can be estimated and, for a determination based upon a single pair of arterial and venous blood samples, the standard error of the determination is 20.0 per cent. In most subjects at least two pairs of $A-V$ differences were obtained, so that generally the standard error of the mean for a single subject is 14.1 per cent. For the entire series of 14 subjects then, the standard error owing to chemical methods is only 3.8 per cent. Moreover if errors from all sources, including errors of chemical analysis, are random, the mean for the entire series is not likely to be far from the true value. Indeed the values appear to be distributed normally about the mean with a median of 6.5 per cent, and it can be shown by routine analysis of the data that it is highly improbable that the true mean is as high as 25 per cent.

The mean value, 7 per cent of $\mathrm{O}_{2}$ uptake used for oxidation of glucose by forearm muscle, may be compared with data reported by Baker, Shreeve, Shipley, Incefy, and Miller (45). These workers assessed glucose oxidation in man by measuring rates of appearance of $\mathrm{C}^{14} \mathrm{O}_{2}$ in expired air following administration of $\mathrm{C}^{14}$-labeled glucose, and their calculations indicate that 21 per cent of $\mathrm{CO}_{2}$ production in the basal state was derived from glucose oxidation by the entire body. If the $R . Q$. in their subjects were 0.82 , the usual mean 
value found by others in subjects in the basal state, glucose would have provided about 17 per cent of the substrate for oxidation throughout the body. As Table VI indicates, although metabolism by muscle accounts probably for nearly 40 per cent of total $\mathrm{O}_{2}$ consumption, it accounts for only 20 per cent of glucose uptake and it is not surprising that measurements of net performance of total body metabolism should lead to a slightly higher estimate of the quantitative role of oxidation of glucose.

\section{Probable inadequacy of muscle glycogen as oxi- dizable substrate in the basal state}

While it is clear that arterial blood supplies little glucose to the arm, it is conceivable that glycogen stored previously (i.e., after meals) serves as carbohydrate substrate under basal conditions. Some evidence is available suggesting that the role of glycogen must be minor.

Glucose A-V differences following meals have been measured by Fryer, Moore, Williams, and Young (46). From their data it can be estimated that about $60 \mathrm{~g}$. of glucose is taken up by total body muscle from 8:00 A.M. to 10:00 P.M. As reported elsewhere (47) the glucose uptake from 10:00 P.M. to 8:00 A.M. averaged $30 \mathrm{~g}$. The total 24-hour glucose uptake, then, about $90 \mathrm{~g}$., could account for 671 . of $\mathrm{O}_{2}$ if it were totally oxidized. Basal $\mathrm{O}_{2}$ consumption by total muscle may be taken as 1251 . per day from our data, and moderate activity might make 2001 . per day a reasonable estimate of total uptake. The $90 \mathrm{~g}$. of glucose then would account for only one-third of the $\mathrm{O}_{2}$ uptake. However, since a considerable part of glucose taken up is lost as lactate, even this minor fraction must be revised downward.

Furthermore, if observations in the rat can be extrapolated to man, then it can be estimated from data of glycogen turnover rates (48) and from decrements in concentration of muscle glycogen (49) that only about 12 per cent of the oxygen consumption can be attributed to glycogen during the basal state.

\section{Respiratory quotient of forearm muscle}

So far, it has been shown that most of the oxygen consumed by muscle under basal conditions is spent in oxidation of non-carbohydrate substrates. A clue concerning the nature of the major sub- strates is found in estimates of R.Q. for forearm muscle, listed in Table VII. The range is broad, 0.64 to 1.02 , but is attributable at least in part to experimental error cumulative in any ratio of $\mathrm{A}-\mathrm{V}$ concentration differences; this error may be calculated and, for a determination of R.Q. based upon a single pair of $\mathrm{A}-\mathrm{V}$ concentration differences, the standard error of the estimated R.Q. is 0.065 . In most of the subjects at least two pairs of arterial and venous bloods were drawn, so that the standard error for the R.Q. of a single subject is usually 0.046 . A large fraction then of the R.Q. range may well be owing to experimental error. The true mean R.Q. for the entire series of 14 subjects is however unlikely to be outside the range of 0.74 to 0.86 .

These data may be compared with those of Harrop (30) who in 1919 measured $\mathrm{O}_{2}$ and $\mathrm{CO}_{2}$ $\mathrm{A}-\mathrm{V}$ differences. Calculation of R.Q. for his 10 subjects yields a median of 0.81 , with a mean which is misleadingly higher owing to a single discrepantly high value.

Although classic interpretation of R.Q. data derived respiratory gases have been, with cause, indicted in recent years (37), the strictures are perhaps not as pertinent to interpretation of forearm muscle R.Q. Those complex metabolic activities which make interpretation of total body R.Q. hazardous are largely the province of the liver. It might be hoped that a plot of R.Q. against the fraction of $\mathrm{O}_{2}$ uptake spent for oxidation of glucose would show a direct correlation. This was not found, very likely because of the cumulative errors involved in the determination of each of these values. More reliance can, however, be placed on the means of the entire series. The true mean R.Q. of this series probably lies between 0.74 and 0.86 , a range which theoretically permits carbohydrate, protein, fat or ketone bodies to serve as the major substrate. The experiments reported here have demonstrated the limited role of carbohydrate: glucose uptake from arterial blood. might account for 0 to 22 per cent of the oxygen consumption (mean \pm 2 standard errors); glycogen in muscle would appear to furnish at most no more than an additional 10 per cent or so. Other possible substrates include all those metabolic intermediates brought to muscle by arterial blood. Some of the more likely candidates are considered below. 
Possible nature of the major substrates for resting muscle

Although amino acids do serve as oxidative substrates, it seems unlikely that amino acids would provide the major substrate 16 hours after a meal, since "no appreciable stores of non-functional protein exists anywhere in the body" (50). Kline (51) could not demonstrate amino acid uptake by the hind limb of the dog; in fact, concentration of amino acids in venous blood exceeded arterial. However, uptake of amino acids has been demonstrated by the intact human heart (25)." Even if $\mathrm{A}-\mathrm{V}$ differences in the human forearm were as large as coronary A-V differences, then only 10 per cent of the oxygen consumption would be accounted for.

The role of ketone bodies similarly must be minor after an overnight fast of only 16 to 19 hours. Uptake is limited by low arterial concentrations of ketone bodies (expressed as $\beta$-hydroxybutyric acid) of 1.33 and $2.26 \mathrm{mg}$. per $100 \mathrm{ml}$. $(52,25)$ obtained under similar fasting conditions. Gammeltoft (53) has studied the A-V ketone difference in the arm of fasting man and found this to average about $1 \mathrm{mg}$. per $100 \mathrm{ml}$. when the arterial concentrations were about 6 to $10 \mathrm{mg}$. per $100 \mathrm{ml}$. It would appear then from the limited data available that ketone bodies could not account for more than 10 per cent of the oxygen substrate.

Fatty acids, however, are present in very high concentration even under fasting conditions, so high, in fact, that only 1 or 2 per cent of plasma lipids need be extracted to account for all the unidentified substrate. Unfortunately, available analytical methods are inadequate to detect such small $\mathrm{A}-\mathrm{V}$ differences and in a number of trials using several methods for total lipid determination we have been unable to prove such differences existed.

There seems to be no reason to doubt that muscle has the apparatus with which to oxidize lipids. Isolated skeletal muscle can oxidize fatty acids (54-57) and uptake of lipid by myocardium in man has been demonstrated (25) by the coronary sinus catheterization technique.

In the face of strong suggestive evidence pointing

\footnotetext{
4 The mean value for $\Delta$ amino acids in Table $I$ in this reference is an obvious misprint and evidently should be one-tenth the value printed.
}

toward a major role for fatty acids, current efforts are being directed toward fractionation of plasma lipids on the assumption that most of the lipid uptake may occur with respect to a single lipid fraction and that the $\mathrm{A}-\mathrm{V}$ differences in this fraction might then be sufficiently large to be measured convincingly. Purely on the basis of relative ease of transcapillary exchange it would appear most probable that the small fraction of fatty acids which are unesterified might be the major substrate.

\section{SUMMARY}

Metabolism of the forearm, a mass of tissue which is predominantly skeletal muscle, has been studied in 14 normal men in the basal state by measuring simultaneously differences in arterial and venous concentrations of $\mathrm{O}_{2}, \mathrm{CO}_{2}$, glucose and lactate. In eight subjects blood flow through the segment was measured also and rates of uptake of $\mathrm{O}_{2}$ and of glucose and of production of $\mathrm{CO}_{2}$ and lactate were determined.

Oxygen consumption by resting muscles of the forearm is vigorous. If it is representative of $\mathrm{O}_{2}$ uptake by all skeletal muscles, then muscle accounts for 35 to 40 per cent of total body $\mathrm{O}_{2}$ uptake at rest and following a 16-hour fast.

In contrast, muscle glucose uptake is relatively small. By a similar extrapolation, muscle accounts for only 20 per cent of total body glucose uptake.

Without exception, venous lactate concentration exceeded arterial; muscle produced lactate continuously even at rest and in the presence of active $\mathrm{O}_{2}$ consumption. On the average, 60 per cent of glucose uptake by forearm muscles was accounted for by lactate production, with wide individual variation.

The remaining glucose, not accounted for by lactate production, was assumed to be oxidized completely. Its oxidation could account for only about 7 per cent of the $\mathrm{O}_{2}$ uptake; that is, glucose abstracted from blood is only a minor fuel for skeletal muscle under these conditions.

Based on estimates of transient glycogen storage and of reported turnover rates for glycogen it is unlikely that glycogen in muscle is oxidized to an important extent in the basal state. Most of the $\mathrm{O}_{2}$ uptake is probably spent in oxidation of non-carbohydrate material in forearm muscle. 
The mean R.Q. of forearm muscle was 0.80 , suggesting that the major non-carbohydrate material which serves as the substrate for oxidation in forearm muscle is lipid.

\section{ACKNOWLEDGMENT}

We are greatly indebted to the patients and to our colleagues who permitted themselves to be subjects for these experiments and to Miss Ellen Rogus and Mrs. Gerda von Ahlefeldt, for their assistance in the conduct of the experiments and in the chemical analyses.

\section{REFERENCES}

1. Andres, R., Cader, G., and Zierler, K. L., Metabolic exchange of human muscle in situ. Am. J. Physical Med., 1955, 34, 286.

2. Andres, R., Cader, G., and Zierler, K. L., Skeletal muscle metabolism in man. Inadequacy of carbohydrate oxidation to account for resting oxygen consumption. Federation Proc., 1955, 14, 5.

3. Kenk, R., and Nall, M. L., Physiology of the circulation of the brain. An annotated bibliography, 1938-1948. Physiol. Rev., 1952, 32, Suppl. No. 1.

4. Bing, R. J., Hammond, M. M., Handelsman, J. C., Powers, S. R., Spencer, F. C., Eckenhoff, J. E., Goodale, W. T., Hafkenschiel, J. H., and Kety, S. S., The measurement of coronary blood flow, oxygen consumption, and efficiency of the left ventricle in man. Am. Heart J., 1949, 38, 1.

5. Cargill, W. H., and Hickam, J. B., The oxygen consumption of the normal and the diseased human kidney. J. Clin. Invest., 1949, 28, 526.

6. Bradley, S. E., Ingelfinger, F. J., Groff, A. E., and Bradley, G. P., Estimated hepatic blood flow and hepatic venous oxygen content in cirrhosis of the liver. Proc. Soc. Exper. Biol. \& Med., 1948, 67, 206.

7. Chauveau, A., Le travail musculaire et l'énergie qu'il représente. Paris, Asselin et Houzeau, 1891.

8. Andres, R., Zierler, K. L., Anderson, H. M., Stainsby, W. N., Cader, G., Ghrayyib, A. S., and Lilienthal, J. L., Jr., Measurement of blood flow and volume in the forearm of man; with notes on the theory of indicator-dilution and on production of turbulence, hemolysis, and vasodilatation by intra-vascular injection. J. Clin. Invest., 1954, 33, 482.

9. Somogyi, M., Determination of blood sugar. J. Biol. Chem., 1945, 160, 69.

10. Nelson, N., A photometric adaptation of the Somogyi method for the determination of glucose. J. Biol. Chem., 1944, 153, 375.

11. Zipf, R. E., and Waldo, A. L., Spectrophotometric analysis of carbohydrates and study of anthrone reagent. J. Lab. \& Clin. Med., 1952, 39, 497.

12. Roe, J. H., The determination of sugar in blood and spinal fluid with anthrone reagent. J. Biol. Chem., 1955, 212, 335.
13. Barker, S. B., and Summerson, W. H., The colorimetric determination of lactic acid in biological material. J. Biol. Chem., 1941, 138, 535.

14. Van Slyke, D. D., and Neill, J. M., The determination of gases in blood and other solutions by vacuum extraction and manometric measurement. I. J. Biol. Chem., 1924, 61, 523.

15. Edholm, O. G., Howarth, S., and McMichael, J., Heart failure and bone blood flow in osteitis deformans. Clin. Sc., 1945, 5, 249.

16. Hardy, J. D., and Soderstrom, G. F., Heat loss from the nude body and peripheral heat flow at temperatures of $22^{\circ} \mathrm{C}$ to $35^{\circ} \mathrm{C}$. J. Nutrition, 1938, 16, 493.

17. Behnke, A. R., and Willmon, T. L., Cutaneous diffusion of helium in relation to peripheral blood flow and the absorption of atmospheric nitrogen through the skin. Am. J. Physiol., 1941, 131, 627.

18. Stewart, H. J., and Evans, W. F., The peripheral blood flow under basal conditions in normal male subjects in the third decade. Am. Heart J., 1943, 26, 67.

19. Hertzman, A. B., Randall, W. C., and Jochim, K. E., Relations between cutaneous blood flow and blood content in the finger pad, forearm, and forehead. Am. J. Physiol., 1947, 150, 122.

20. Cooper, K. E., Edholm, O. G., and Mottram, R. F., The blood flow in skin and muscle of the human forearm. J. Physiol., 1955, 128, 258.

21. Hertzman, A. B., and Randall, W. C., Further studies on the correlation between skin volume pulses and blood flow. Federation Proc., 1948, 7, 54.

22. Abramson, D. I., and Ferris, E. B., Jr., Responses of blood vessels in the resting hand and forearm to various stimuli. Am. Heart J., 1940, 19, 541.

23. Singer, R. B., and Hastings, A. B., An improved clinical method for the estimation of disturbances of the acid-base balance of human blood. Medicine, 1948, 27, 223.

24. Mitchell, A. M., and Cournand, A., The fate of circulating lactic acid in the human lung. J. Clin. Invest., 1955, 34, 471.

25. Ungar, I., Gilbert, M., Siegel, A., Blain, J. M., and Bing, R. J., Studies on myocardial metabolism. IV. Myocardial metabolism in diabetes. Am. J. Med., 1955, 18, 385.

26. Hummel, J. P., The fluorometric determination of malic acid. J. Biol. Chem., 1949, 180, 1225.

27. Rothman, S., Physiology and Biochemistry of the Skin. Chicago, Univ. of Chicago Press, 1954.

28. Christison, R., An inquiry on some disputed points in the chemical physiology of the blood and respiration. I. On the mutual action of blood and atmospheric air. Edinburgh Med. \& Surg. J., 1831, $35,94$.

29. Stadie, W. C., The oxygen of the arterial and venous blood in pneumonia and its relation to cyanosis. J. Exper. Med., 1919, 30, 215. 
30. Harrop, G. A., Jr., The oxygen and carbon dioxide content of arterial and of venous blood in normal individuals and in patients with anemia and heart disease. J. Exper. Med., 1919, 30, 241.

31. Keys, A., The oxygen saturation of the venous blood in normal human subjects. Am. J. Physiol., 1938, 124, 13.

32. Mottram, R. F., The oxygen consumption of human skeletal muscle in vivo. J. Physiol., 1955, 128, 268.

33. Weiss, S., Parker, F., Jr., and Robb, G. P., A correlation of hemodynamics, function, and histologic structure of the kidney in malignant arterial hypertension with malignant nephrosclerosis. Ann. Int. Med., 1933, 6, 1599.

34. Bell, D. M., Femoral arteriovenous sugar differences in fasting human beings. J. Lab. \& Clin. Med., 1952, 40, 337.

35. Peters, J. P., Jr., Barr, D. P., and Rule, F. D., I. The carbon dioxide absorption curve and carbon dioxide tension of the blood of normal resting individuals. J. Biol. Chem., 1921, 45, 489.

36. Somogyi, M., Studies of arteriovenous differences in blood sugar. I. Effect of alimentary hyperglycemia on the rate of extrahepatic glucose assimilation. J. Biol. Chem., 1948, 174, 189.

37. Soskin, S., and Levine, R., Carbohydrate Metabolism; Correlation of Physiological, Biochemical and Clinical Aspects. Chicago, Univ. of Chicago Press, 1946.

38. Holling, H. E., Observations on the oxygen content of venous blood from the arm vein and on the oxygen consumption of resting human muscle. Clin. Sc., 1939, 4, 103.

39. Means, J. H., The Thyroid and Its Diseases. 2nd ed., Philadelphia, J. B. Lippincott Co., 1948.

40. Myers, J. D., Net splanchnic glucose production in normal man and in various disease states. J. Clin. Invest., 1950, 29, 1421.

41. Scheinberg, P., and Stead, E. A., Jr., The cerebral blood flow in male subjects as measured by the nitrous oxide technique. Normal values for blood flow, oxygen utilization, glucose utilization, and peripheral resistance, with observations on the effect of tilting and anxiety. J. Clin. Invest., 1949, 28, 1163.

42. Smith, H. W., The Kidney: Structure and Function in Health and Disease. New York, Oxford Univ. Press, 1951.

43. Levitan, B. A., Unpublished results. Quoted in reference 40 .

44. Barron, E. S. G., The oxidative pathways of carbohydrate metabolism in Modern Trends in Physiology and Biochemistry, Ed., New York, Barron, E. S. G., Academic Press, Inc., 1952, p. 471.

45. Baker, N., Shreeve, W. W., Shipley, R. A., Incefy, G. E., and Miller, M., $C^{\text {t4 }}$ studies in carbohydrate metabolism. I. The oxidation of glucose in normal human subjects. J. Biol. Chem., 1954, 211, 575.

46. Fryer, J. H., Moore, N. S., Williams, H. H., and Young, C. M., A study of the interrelationship of the energy-yielding nutrients, blood glucose levels, and subjective appetite in man. J. Lab. \& Clin. Med., 1955, 45, 684.

47. Zierler, K. L., and Andres, R., Carbohydrate metabolism in intact skeletal muscle in man during the night. Submitted for publication.

48. Stetten, DeW., Jr., and Boxer, G. E., Studies in carbohydrate metabolism. I. The rate of turnover of liver and of carcass glycogen, studied with the aid of deuterium. J. Biol. Chem., 1944, $155,231$.

49. Hershey, J. M., and Orr, M. D., The removal of glycogen from living muscle. Trans. Roy. Soc. Canada, (Sect. V, Biol. Sc.), 1928, 22, 151.

50. Handler, P., Protein as a metabolic fuel in The Major Metabolic Fuels. Brookhaven Symposia in Biology No. 5, Brookhaven National Laboratory, Upton, N. Y., 1952, p. 99.

51. Kline, D. L., Effect of alloxan, pancreatectomy and adrenalectomy on plasma amino nitrogen in the dog as studied by means of hemorrhage. Am. J. Physiol., 1948, 154, 87.

52. Werk, E. E., Jr., McPherson, H. T., Hamrick, L. W., Jr., Myers, J. D., and Engel, F. L., Studies on ketone metabolism in man. I. A method for the quantitative estimation of splanchnic ketone production. J. Clin. Invest., 1955, 34, 1256.

53. Gammeltoft, A., Significance of ketone bodies in fat metabolism. I. Concentration of ketone bodies in the arterial and venous blood in human subjects during starvation. Acta physiol. Scandinav., 1949, 19, 270.

54. Geyer, R. P., Matthews, L. W., and Stare, F. J., Metabolism of emulsified trilaurin (- $\left.\mathrm{C}^{16} \mathrm{OO}-\right)$ and octanoic acid (-C $\mathrm{C}^{14} \mathrm{OO}-$ ) by rat tissue slices. J. Biol. Chem., 1949, 180, 1037.

55. Weinhouse, S., Mullington, R. H., and Volk, M. E., Oxidation of isotopic palmitic acid in animal tissues. J. Biol. Chem., 1950, 185, 191.

56. Wertheimer, E., and Ben-Tor, V., Fat utilization by muscle. Biochem. J., 1952, 50, 573.

57. Hansen, R. G., and Rutter, W. J., Fatty acid metabolism of rat diaphragm. J. Biol. Chem., 1952, 195, 121. 